\title{
Balanço hídrico e classificação climática para o município de Turiaçu-MA
}

\author{
Mádilo Lages Vieira Passos ${ }^{1}$, Jarlyson Brunno Costa Souza ${ }^{1}$, Telmo José Mendes ${ }^{1 *}$
}

\begin{abstract}
RESUMO: O balanço hídrico é uma ferramenta de caraterização temporal da dinâmica de água no solo de determinada região. Objetivou-se estimar o balanço hídrico climático e a classificação do clima do município de Turiaçu-MA. Foram utilizados séries de dados históricos entre os anos de 1961 a 2016, de precipitação pluviométrica e temperatura mensais, sendo excluídos dados omitidos. Para o cálculo do balanço hídrico climatológico, foi adotado o valor de $100 \mathrm{~mm}$ para a capacidade de água disponível (CAD). A classificação climática foi obtida por meio dos valores do índice hídrico (Ih), índice de aridez (Ia) e índice de umidade (Iu). A evapotranspiração potencial atingiu valores médios anuais de 1765,3 mm. A deficiência hídrica total anual verificada foi de $535,3 \mathrm{~mm}$, distribuído em sua totalidade ao longo do período de estiagem da região (agosto a dezembro). A fórmula climática obtida foi $\mathrm{B}_{1} \mathrm{sA}$ 'a', isto é, clima úmido, megatérmico, com deficiência hídrica moderada no verão e $26,6 \%$ da evapotranspiração anual concentrada no trimestre mais quente do ano.
\end{abstract}

Palavras-chave: climatologia, deficiência hídrica, evapotranspiração potencial.

\section{Water balance and climate classification for the municipality of Turiaçu-MA}

ABSTRACT: The water balance is a tool for the temporal characterization of soil water dynamics in a given region. The objective was to estimate the climatic water balance and the climate classification of the municipality of Turiaçu-MA. Were used historical data series between the years of 1961 to 2016, of rainfall and monthly temperature, being deleted data omitted. For the calculation of the climatological water balance, the value of $100 \mathrm{~mm}$ for the available water capacity (ADC) was adopted. The climatic classification was obtained through the values of the water index (Ih), aridity index (Ia) and moisture index (Iu). The potential evapotranspiration reached annual mean values of $1765.3 \mathrm{~mm}$. The total annual water deficit verified was $535.3 \mathrm{~mm}$, distributed in its entirety during the period of drought in the region (August to December). The climate formula obtained was $\mathrm{B}_{1} \mathrm{sA}^{\prime} \mathrm{a}$ ', that is, humid climate, megathermic, with moderate water deficiency in the summer and $26.6 \%$ of the annual evapotranspiration concentrated in the hottest of the year quarter.

Keywords: climatology, water deficiency, potential evapotranspiration.

\section{INTRODUÇÃO}

O método de estimativa do balanço hídrico climatológico (BHC) proposto por Thornthwaite e Mather (1955) é uma ferramenta de monitoramento do armazenamento de água no solo, utilizada como instrumento de planejamento estratégico agrícola (PASSOS et al., 2017a).

O conhecimento das variáveis que compõem o $\mathrm{BHC}$ favorece o planejamento agropecuário e as práticas de controle de produção, ou seja, disponibiliza informações que permitem aos produtores identificar as fragilidades climáticas, sendo uma ferramenta essencial para o sucesso de um empreendimento agrícola, que inclui a decisão de optar ou não por sistemas de irrigação para suprir a deficiência hídrica no solo (AQUINO, OLIVEIRA, 2013).

A metodologia de cálculo do BHC considera o solo e a sua textura física, a profundidade efetiva do sistema radicular das plantas e o movimento de água da localidade durante todo o ano (MATOS et al., 2014).

Segundo Matos et al. (2015), o método proposto por Thornthwaite e Mather (1955) contabiliza a água do solo, considerando a precipitação pluvial como ganho e a evapotranspiração representa a perda de umidade do solo, podendo-se estimar os valores correspondentes ao Excedente Hídrico (EXC) e a Deficiência Hídrica (DEF).

Realizado o cálculo do balanço hídrico, tornase tarefa simples executar a classificação climática de Thornthwaite (1948), porque os dados necessários são justamente variáveis já determinadas na resolução do BHC (DANTAS et al., 2007).

\footnotetext{
Recebido em 14/01/2018; Aceito para publicação em 06/06/2018

${ }^{1}$ Universidade Federal do Maranhão

*E-mail: engtelmo@yahoo.com.br
} 
Classificar o clima de determinada região é definir os limites geográficos dos diferentes tipos de clima e é suficiente para avaliação do crescimento de plantas e animais, porém, não auxilia na previsão do tempo (CUNHA; MARTINS, 2009).

A delimitação do clima de uma região, permite estabelecer os indicadores do potencial do meio físico para o local em estudo, bem como os limites das áreas homogêneas, contribuindo para o planejamento e desenvolvimento sustentável da região (MEDEIROS et al., 2013a).

Para Rolim et al. (2007), o sistema de classificação climática de Thornthwaite, é o mais adequado no âmbito agrícola, pois considera a planta como um meio físico pelo qual é possível conduzir água do solo para atmosfera.

A estimativa do balanço hídrico climatológico de Thornthwaite e Mather (1955) e a classificação agroclimática de Thornthwaite (1948) são ferramentas amplamente utilizadas, como pode ser verificado nos trabalhos de Medeiros et al. (2013b), Souza et al. (2013), Medeiros et al. (2015a), Medeiros et al. (2015b) e Jesus (2015).

Objetivou-se realizar a estimativa do balanço hídrico climatológico proposto por Thornthwaite e Mather (1955) e a classificação climática segundo Thornthwaite (1948), para o município de Turiaçu-MA.

\section{MATERIAL E MÉTODOS}

O balanço hídrico climático (BHC) e a caracterização do clima foram realizados para o município de Turiaçu-MA (Figura 1). As coordenadas geográficas do local são $01^{\circ} 39^{\prime}$ de latitude sul e $45^{\circ} 22^{\prime}$ de longitude oeste.

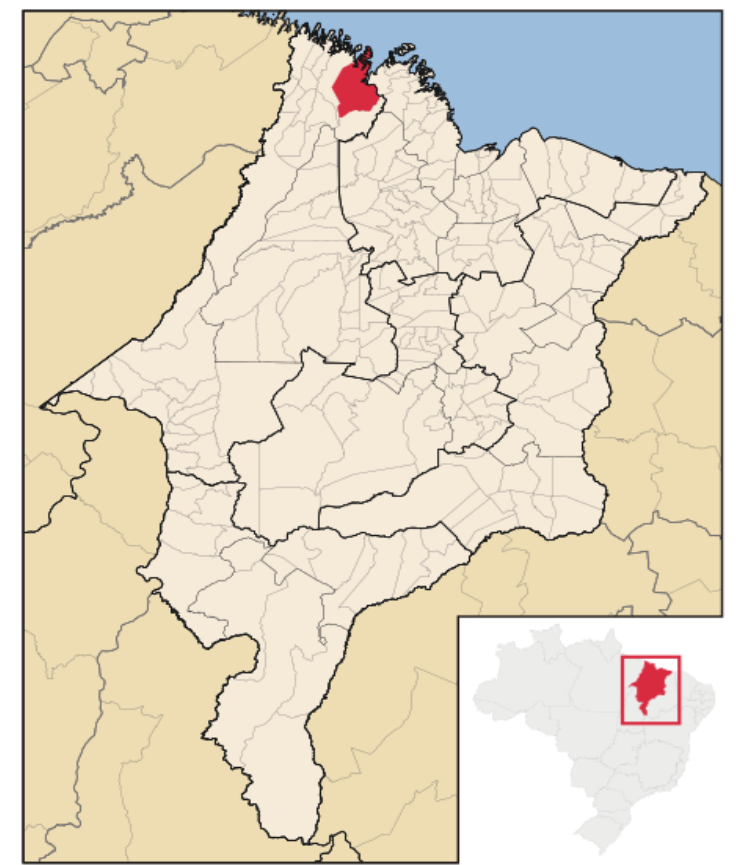

Figura 1 - Mapa do estado do Maranhão, em destaque o município de Turiaçu. Fonte. WIKIMEDIA, (2017).

A localidade de estudo situa-se na Mesorregião do Oeste Maranhense dentro da Microrregião do Gurupi e está inserido na área da Amazônia Maranhense. A população estimada do município é de $34.949,0$ habitantes e uma área de unidade territorial de $2578,5 \mathrm{~km}^{2}$, segundo dados do IBGE (2017).

O clima da região, segundo classificação de Köppen é do tipo Aw', semiúmido, com temperatura média anual de $26,4^{\circ} \mathrm{C}$, umidade relativa do ar de $82 \%$. A precipitação total anual alcança 2196 mm (ARAUJO et al., 2012).
O cálculo do BHC foi efetuado, adotando-se o valor de $100 \mathrm{~mm}$ para a capacidade de água disponível no solo (CAD). Os valores médios mensais de temperatura e precipitação pluvial foram obtidos a partir da estação meteorológica convencional do Instituto Nacional de Meteorologia (INMET) cujo código da Organização Mundial de Meteorologia (OMM) é 82198. A estação localiza-se nas coordenadas $01^{\circ}$ $33^{\prime}$ de latitude sul, $45^{\circ} 21^{\prime}$ de longitude oeste e altitude de $44,1 \mathrm{~m}$. A série histórica de temperatura e precipitação compreendeu o período entre os anos de 1961 a 2016, sendo 
desconsiderados aqueles dados que, por algum motivo, não foram registrados.

A evapotranspiração potencial (ETP) foi estimada pelo método de Thornthwaite (1948). Utilizando-se os valores de precipitação e ETP, estimou-se a evapotranspiração real (ETR), o armazenamento de água do solo (ARM), a deficiência hídrica (DEF) e o excedente hídrico (EXC).

A classificação climática foi realizada por meio dos valores do índice hídrico (Ih) equação 1 , índice de aridez (Ia) equação 2 e índice de umidade (Iu) equação 3.

Índice hídrico:

$$
\mathrm{Ih}=\frac{\mathrm{EXC}}{\mathrm{ETP}} 100 \quad \text { (Equação 1) }
$$

Índice de aridez:

$$
\mathrm{Ia}=\frac{\mathrm{DEF}}{\mathrm{ETP}} 100 \quad(\text { Equação } 2)
$$

Índice de umidade:

$$
\mathrm{Iu}=\mathrm{Ih}-0,6 \mathrm{Ia} \quad \text { (Equação 3) }
$$

em que: EXC: excedente hídrico (mm); ETP: evapotranspiração potencial anual $(\mathrm{mm})$; DEF: deficiência hídrica (mm); Ih: índice hídrico; Ia: índice de aridez; e Iu: índice de umidade.

\section{RESULTADOS E DISCUSSÃO}

$\mathrm{Na}$ Tabela 1 estão disponíveis os resultados do balanço hídrico climático. Nela, constam os valores médios mensais das variáveis temperaturas $\left(\mathrm{T} ;{ }^{\circ} \mathrm{C}\right)$, precipitação pluvial $(\mathrm{P}$; $\mathrm{mm})$, evapotranspiração potencial (ETP; mm), armazenamento de água no solo (ARM; mm), evapotranspiração real (ETR; mm), excedente hídrico (EXC; mm) e deficiência hídrica (DEF; $\mathrm{mm})$.

Tabela 1 - Balanço hídrico climatológico pelo método de Thornthwaite e Mather (1955) para o período de 1961 a 2016 , Turiaçu-MA.

\begin{tabular}{ccccccccccc}
\hline Mês & $\begin{array}{c}\text { T } \\
\left({ }^{\mathbf{O}}\right)\end{array}$ & $\begin{array}{c}\mathbf{P} \\
(\mathbf{m m})\end{array}$ & $\begin{array}{c}\text { ETP } \\
(\mathbf{m m})\end{array}$ & $\begin{array}{c}\text { P-ETP } \\
(\mathbf{m m})\end{array}$ & $\begin{array}{c}\text { NEG.AC } \\
(\mathbf{m m})\end{array}$ & $\begin{array}{c}\text { ARM } \\
(\mathbf{m m})\end{array}$ & $\begin{array}{c}\text { ALT } \\
(\mathbf{m m})\end{array}$ & $\begin{array}{c}\text { ETR } \\
(\mathbf{m m})\end{array}$ & $\begin{array}{c}\text { DEF } \\
(\mathbf{m m})\end{array}$ & $\begin{array}{c}\text { EXC } \\
(\mathbf{m m})\end{array}$ \\
\hline Jan & 27,4 & 202,8 & 150,6 & 52,2 & $-64,7$ & 52,4 & 52,2 & 150,6 & 0,0 & 0,0 \\
Fev & 26,9 & 324,8 & 131,5 & 193,3 & 0,0 & 100,0 & 47,6 & 131,5 & 0,0 & 145,7 \\
Mar & 26,7 & 449,5 & 143,2 & 306,3 & 0,0 & 100,0 & 0,0 & 143,2 & 0,0 & 306,3 \\
Abr & 26,8 & 408,3 & 138,9 & 269,4 & 0,0 & 100,0 & 0,0 & 138,9 & 0,0 & 269,4 \\
Maio & 27,1 & 299,3 & 145,9 & 153,4 & 0,0 & 100,0 & 0,0 & 145,9 & 0,0 & 153,4 \\
Jun & 27,1 & 202,8 & 140,9 & 61,9 & 0,0 & 100,0 & 0,0 & 140,9 & 0,0 & 61,9 \\
Jul & 27,0 & 153,6 & 144,8 & 8,8 & 0,0 & 100,0 & 0,0 & 144,8 & 0,0 & 8,8 \\
Ago & 27,6 & 48,8 & 150,6 & $-101,8$ & $-101,8$ & 36,1 & $-63,9$ & 112,7 & 37,9 & 0,0 \\
Set & 28,0 & 13,6 & 149,6 & $-136,0$ & $-237,8$ & 9,3 & $-26,8$ & 40,4 & 109,2 & 0,0 \\
Out & 28,2 & 11,5 & 156,9 & $-145,4$ & $-383,2$ & 2,2 & $-7,1$ & 18,6 & 138,3 & 0,0 \\
Nov & 28,4 & 10,9 & 153,9 & -143 & $-526,2$ & 0,5 & $-1,7$ & 12,6 & 141,3 & 0,0 \\
Dez & 28,3 & 49,6 & 158,5 & $-108,9$ & $-635,1$ & 0,2 & $-0,3$ & 49,9 & 108,6 & 0,0 \\
\hline Total & - & 2175,5 & 1765,3 & 410,2 & - & 700,7 & 0,0 & 1230,0 & 535,3 & 945,5 \\
\hline
\end{tabular}

T - Temperatura do ar; P - Precipitação; ETP - Evapotranspiração Potencial; P-ETP - Quantidade de água que permanece no solo; NEG.AC - Negativo Acumulado; ARM - Armazenamento de água no solo; ALT - ARMatual - ARManterior; ETR Evapotranspiração real; DEF - Deficiência Hídrica e EXC - Excedente Hídrico.

A temperatura média mensal mais elevada foi verificada para novembro, seguido de dezembro, com 28,4 e $28,3{ }^{\circ} \mathrm{C}$, respectivamente. Março possui a menor média térmica mensal $26,7^{\circ} \mathrm{C}$. A temperatura média anual estimada para o município é $27,6{ }^{\circ} \mathrm{C}$, apresentando pequena variabilidade.

A partir do estudo da série climatológica de precipitação pluviométrica, observou-se que a maior altura pluviométrica foi registrada no ano de 1985 , com 3579,2 mm, e a menor no ano de 1983, com 733,8 mm. Passos et al. (2017a) verificaram para o município de Balsa-MA, que 1985 foi o ano mais chuvoso, com 1999,0 mm, e 1982 o ano menos chuvoso, com 566,5 mm.

De acordo com a Figura 2, verifica-se uma distribuição sazonal da precipitação pluviométrica, a qual atinge valores médios anuais de $2175,5 \mathrm{~mm}$. 


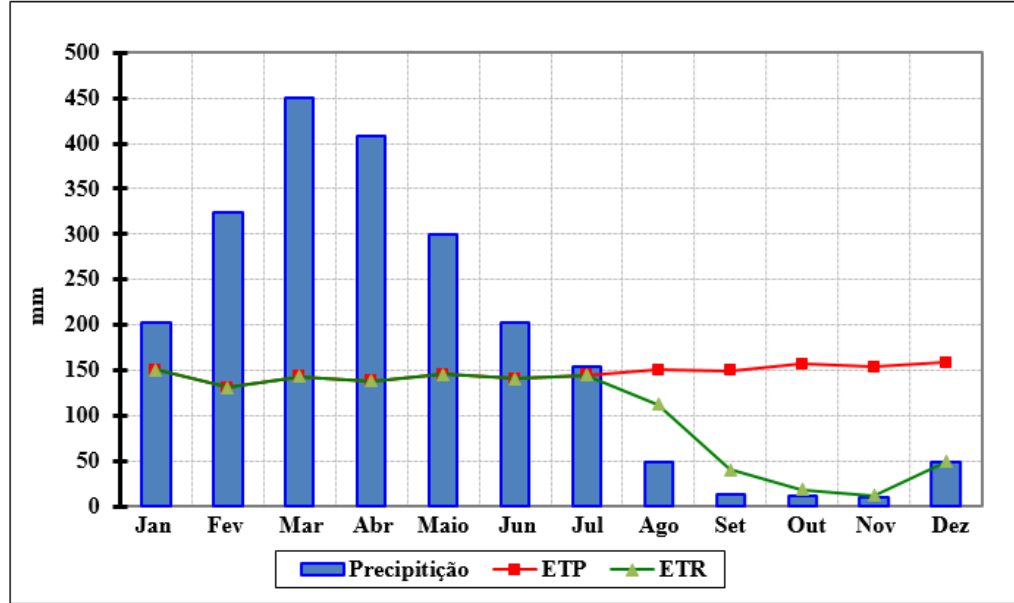

Figura 2 - Gráfico do balanço hídrico para Turiaçu-MA. Método de Thornthwaite e Mather (1955), para o período de 1961 a 2016.

A sazonalidade das chuvas define duas estações. A primeira, estação úmida, ocorre de janeiro a julho com índices pluviométricos mensais flutuando entre $153,6 \mathrm{~mm}$ a $449,5 \mathrm{~mm}$ e um total de 2041,0 mm, no qual corresponde a cerca de $94 \%$ do precipitado anualmente. A segunda, estação seca, estende-se ao longo dos meses de agosto a dezembro, com oscilações na altura pluviométrica de $10,9 \mathrm{~mm}$ a 49,6 e um total de $134,3 \mathrm{~mm}$, respondendo por cerca de $16 \%$ acumulado, estes índices são insuficientes para a agricultura alimentada pela chuva. O mês de março teve os maiores valores de precipitação, com um total médio mensal de $449,5 \mathrm{~mm}$ e o mês de setembro foi o menos chuvoso com 10,9 mm.

Para o município de Chapadinha-MA, situado na Mesorregião do Leste Maranhense, Passos et al. (2017b) também verificaram duas estações bem definidas, a estação úmida ocorre de janeiro a maio, respondendo por cerca de $84 \%$ do total precipitado e a estação seca, de junho a dezembro respondendo por cerca de $16 \%$ do total acumulado. Também verificaram o mês de março com a maior média mensal $(350,9 \mathrm{~mm})$ e o mês de setembro o menos chuvoso com $6,4 \mathrm{~mm}$.

Lucena et al. (2016), para o estado do Piauí, obtiveram os maiores volumes de precipitações para os meses de janeiro a abril, oscilando de 124,8 a $169,9 \mathrm{~mm}$ e os menores índices pluviométricos nos meses de junho a outubro, com oscilações de 1,6 a 17,2 mm.

Menezes et al. (2010) afirmam que a grande variabilidade anual e interanual da precipitação pluvial são características marcantes na região Nordeste do Brasil, o que acarreta prejuízos econômicos e sociais aos estados.

Para Silva et al. (2011) a estação chuvosa em todos os estados da região Nordeste do Brasil coincide com a época do ano em que a Zona de Convergência Intertropical (ZCIT) está mais ao Sul, que corresponde aos meses de março, abril e maio (trimestre chuvoso). A ZCIT é mais significativa sobre os Oceanos e por isso, a Temperatura da Superfície do Mar (TSM) é um dos fatores determinantes na sua posição e intensidade (FUCEME, 2017).

Em decorrência das temperaturas médias mensais elevadas, o município possui altas taxas evapotranspirativas. A evapotranspiração potencial (ETP) anual total foi de $1765,3 \mathrm{~mm}$, com variações de $158,5 \mathrm{~mm}$ no mês de dezembro a $131,5 \mathrm{~mm}$ no mês de fevereiro (Tabela 1 ).

Passos et al. (2016) realizaram o cálculo do BHC e classificação climática para uma determinada região de Chapadinha-MA e averiguaram a ETP anual de $1802,5 \mathrm{~mm}$, sendo os meses com maiores e menores evapotranspirações potencial outubro e junho, com 206,3 mm e 136,2 mm, respectivamente. Medeiros et al. (2013b), para o município de Barbalha-CE, averiguaram que a evapotranspiração potencial (ETP) apresentou uma taxa anual média de $1652,8 \mathrm{~mm}$, com variações de $127,2 \mathrm{~mm}$ no mês de junho a 150,1 $\mathrm{mm}$ no mês de dezembro.

Constata-se pela Figura 3, que de janeiro a julho a evapotranspiração potencial e real coincidem, indicando a evaporação máxima para o período, nas condições climatológicas observadas, justificada pela grande quantidade de água disponibilizada no solo. Em contrapartida, nos demais meses do ano a evapotranspiração real fica abaixo da potencial, comportamento justificado pelas elevadas temperaturas e baixa disponibilidade de água durante esse período (LEE, 2014). 
Para Aracaju-SE, Jesus (2015) verificou valores de evapotranspiração potencial e real equivalentes, entre os meses de março a agosto e nos outros meses do ano a evapotranspiração real é inferior à potencial.

Para o armazenamento de água no solo, na estação chuvosa (janeiro a julho) têm-se os maiores índices, flutuando entre 52,4 e 100,0 $\mathrm{mm}$, conforme Tabela 1 . Na estação seca (agosto a dezembro) os níveis de armazenamento oscilam de 0,2 a $36,1 \mathrm{~mm}$, não sendo suficiente à contribuição agrícola.

Ao longo do período de estiagem, observa-se, a partir da Tabela 1, taxas evapotranspirativas superiores aos índices pluviométricos. Segundo Araújo (2011) é por esse motivo que geralmente o balanço hídrico das cidades da região Nordeste apresentam deficiência hídrica. Nesse sentido, Santos et al. (2010) afirmam ser indispensável o fornecimento artificial de água para assegurar a produção agrícola em localidades com déficit de água no solo. Para Matos et al. (2015) a avaliação do comportamento da deficiência hídrica auxilia no planejamento agrícola, no que se refere há uma agricultura mais segura e economicamente viável.

De acordo com a Figura 3, o período de deficiência hídrica na região em estudo, fica totalmente compreendido nos meses que abrangem a estação seca, com valores oscilando entre $37,9 \mathrm{~mm}$ no mês de agosto e $141,3 \mathrm{~mm}$ para novembro, atingindo $535,3 \mathrm{~mm}$ anuais. De fevereiro a julho, há ocorrência de excedente hídrico, com índices flutuando entre 8,8 e 306,3 $\mathrm{mm}$, totalizando $945,5 \mathrm{~mm}$. Nesse período, o solo teoricamente tem umidade apropriada ao crescimento e ao desenvolvimento das culturas agrícolas.

Para Amarante-PI, Medeiros et al. (2013a), averiguaram deficiência hídrica com os índices oscilando entre $15,7 \mathrm{~mm}$ no mês de dezembro a $180,9 \mathrm{~mm}$ no mês de setembro, totalizando 847,2 mm anuais e excedente hídrico total de 287,3 $\mathrm{mm}$, com flutuações de $66,1 \mathrm{~mm}$ no mês de fevereiro a 147,5 $\mathrm{mm}$ em março.

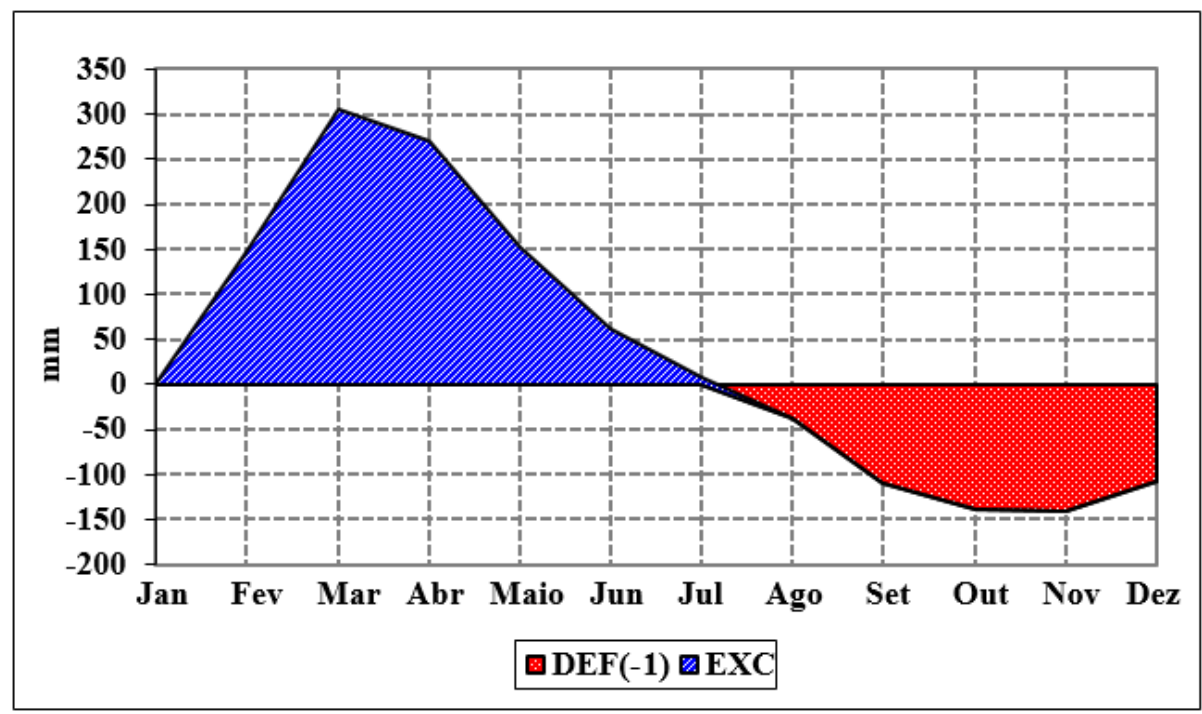

Figura 3 - Deficiência hídrica e excedente hídrico de Turiaçu-MA no período de 1961 a 2016.

Nota-se na Figura 4, que a partir do mês de agosto (estação seca) tem início o processo de retirada de água do solo tendo por consequência a ocorrência do déficit hídrico na região. No início da estação úmida as primeiras chuvas são empregadas na reposição da água solo até que esse atinja sua capacidade máxima de armazenamento de água, isto é, igualando-se ao valor da $\mathrm{CAD}$, quando então aparece excedente hídrico. A época de recarga do solo foi verificada nos meses de janeiro e fevereiro.
Para o município de Chapadinha-MA, Passos et al. (2016), observaram a ocorrência de retirada da água do solo ocorre de junho a dezembro e o período de reposição da água do solo também ocorre nos meses de janeiro e fevereiro. Passos et al. (2017a), para o município de Balsas, averiguaram que em abril inicia-se o processo de retirada de água do solo e a época de recarga do solo ocorre nos meses de dezembro, janeiro e fevereiro. 


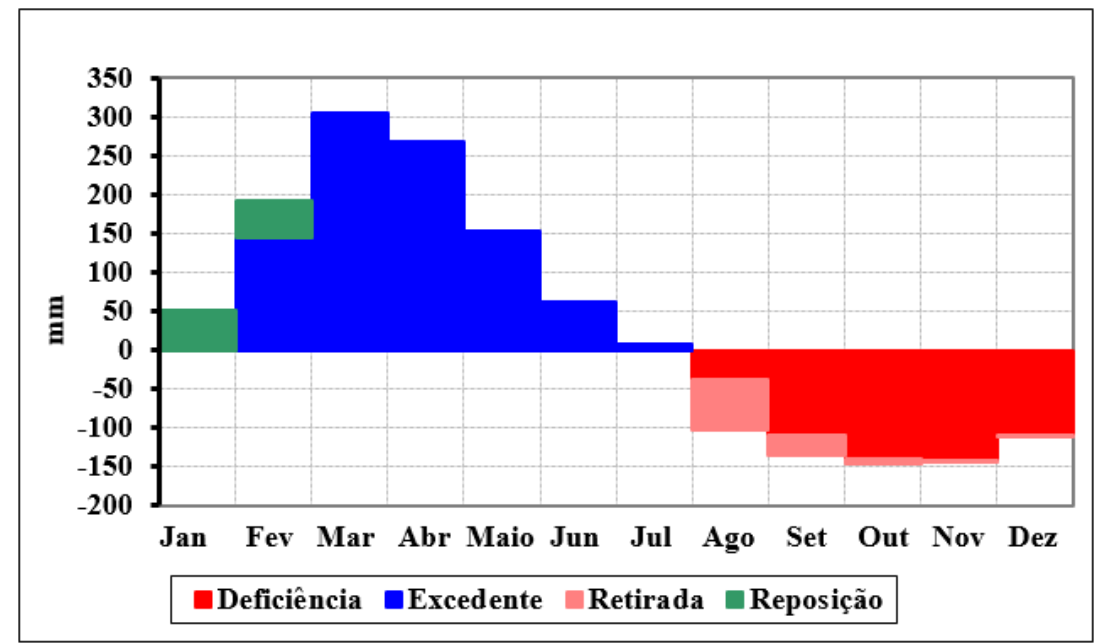

Figura 4 - Extrato do balanço hídrico normal mensal de Turiaçu-MA para o período de 1961 a 2016.

Com relação a classificação climática, a primeira chave foi obtida através do índice de umidade (Iu), para qual foi encontrada a tipologia $B_{1}$ indicando clima úmido. Com base nos índices de aridez (Ia) e hídrico (Ih), determinou-se o subtipo s, que indica deficiência hídrica moderada no verão. Quanto ao fator térmico, determinado por meio da evapotranspiração potencial anual (ETP), verificouse o tipo A', isto é, megatérmico.

Pela relação entre a concentração de evapotranspiração potencial no verão e a evapotranspiração potencial anual, obteve-se o subtipo a'. Assim, a fórmula climática completa obtida foi $\mathrm{B}_{1} \mathrm{sA}^{\prime} \mathrm{a}$, ou seja, clima úmido, megatérmico, com deficiência hídrica moderada no verão e $26,6 \%$ da evapotranspiração anual concentrada no trimestre mais quente do ano.

\section{CONCLUSÕES}

1. A partir dos elementos climáticos de entrada temperatura e precipitação pluviométrica estimou-se todas as variáveis do balanço hídrico climatológico, para o município de Turiaçu-MA.

2. Pelos dados do BHC, a classificação climática evidenciou tratar-se de uma localidade com clima úmido, megatérmico, com deficiência hídrica moderada no verão e $26,6 \%$ da evapotranspiração anual concentrada no trimestre mais quente do ano.

\section{REFERÊNCIAS}

AQUINO, C.M.S., OLIVEIRA, J.G.B. Emprego do Método de Thornthwaite \& Mather (1955) para Cálculo do Balanço Hídrico Climatológico do Núcleo de Degradação de São Raimundo Nonato-Piauí. Revista Brasileira de Geografia Física, v.6, n.1, p.79-90, 2013.
ARAÚJO, S.M.S. A Região semiárida do nordeste do Brasil: Questões Ambientais e Possibilidades de uso Sustentável dos Recursos. Rios Eletrônica, v.5, n.5, p.8998, 2011.

ARAUJO, J.R.G., AGUIAR JÚNIOR, R.A., CHAVES, A.M.S., REIS, F.O., MARTINS, M.R. Abacaxi 'turiaçu': cultivar tradicional nativa do Maranhão. Revista brasileira de fruticultura, Maranhão, v.34, n.4, p.112126, 2012.

CUNHA, A.R., MARTINS, D. Classificação climática para os municípios de Botucatu e São Manuel, SP. Irriga, Botucatu, v.14, n.1, p.1-11, 2009.

DANTAS, A.A.A., CARVALHO, L.G. de, FERREIRA, E. Classificação e tendências climáticas em Lavras, MG. Ciência e Agrotecnologia, Lavras, v.31, n.6, p.18621866, 2007.

FUCEME. SISTEMAS METEOROLÓGICOS CAUSADORES DE CHUVA NA REGIÃO NORDESTE DO BRASIL. Disponível em: <http://www.funceme.br/produtos/script/chuvas/Grafico_ chuvas_postos_pluviometricos/entender/entender2.htm>. Acesso em: 01/05/2017.

IBGE. Instituto Brasileiro de Geografia e Estatística. Disponível em: < http://cidades.ibge.gov.br/xtras/perfil.php?codmun=21124 0>. Acesso em: 01/05/2017.

JESUS, J.B. Estimativa do balanço hídrico climatológico e classificação climática pelo método de Thornthwaite e Mather para o município de Aracaju - SE. Scientia Plena, v.11, n.5, 2015.

LEE W.V. Historical global analysis of occurrences and human casualty of extreme temperature events (ETEs). Natural hazards, v.70, n.2, p.1453-1505, 2014.

LUCENA, D.B., MEDEIROS, R.M., SABOYA, L.M.F., NASCIMENTO, P.L. Aptidão e zoneamento 
agroclimático da palma forrageira para o Estado do Piauí. Revista Brasileira de Agricultura Irrigada, v.10, n.4, p. 809-819, 2016.

MATOS, R.M., MEDEIROS, R.M., FRANCISCO, P.R.M., SILVA, P.F., SANTOS, D. Caracterização e aptidão climática de culturas para o município de Alhandra - PB, Brasil. Revista Brasileira de Agricultura Irrigada, v.9, n.3, p.183-192, 2015.

MATOS, R.M., SILVA, J.A.S., MEDEIROS, R.M. Aptidão climática para a cultura do feijão caupi do município de Barbalha-CE. Revista Brasileira de Agricultura Irrigada, v.8, n.6, p.422-431, 2014.

MEDEIROS, R.M., AZEVEDO, P.V., SABOYA, L.M.F., FRANCISCO, P.R.M. Classificação climática e zoneamento agroclimático para o município de AmarantePI. Revista Brasileira de Agricultura Irrigada, v.7, n.2, p.170-180, 2013a.

MEDEIROS, R.M., SILVA, J.A.S., SILVA, A.O., MATOS, R.M., BALBINO, D.P. Balanço hídrico climatológico e classificação climática para a área produtora da banana do município de Barbalha, CE. Revista Brasileira de Agricultura Irrigada, v.7, n.4, p. 258-268, 2013b.

MEDEIROS, R.M., FRANCISCO, P.R.M., SANTOS, D. Balanço hídrico e erosividade em função das mudanças climáticas no estado da Paraíba. Revista Brasileira de Geografia Física, v.8, n.4, p.1068-1084, 2015 a.

MEDEIROS, R. M., MATOS, R. M., OLIVEIRA, R. C. S., SILVA, P. F., SABOYA, L. M.F. Balanço hídrico climatológico e classificação climática de cultivo de banana em Lagoa Seca - PB. Revista Verde de Agroecologia e Desenvolvimento Sustentável, v.10, n.1, p. 223-228, 2015b.

MENEZES, H.E.A., de BRITO, J.I.B., LIMA, R.A.F.A. Veranico e a produção agrícola no Estado da Paraíba, Brasil. Revista Brasileira de Engenharia Agrícola e Ambiental, v.14, n.2, p.181-186, 2010.

PASSOS, M.L.V., ZAMBRZYCKI, G.C., PEREIRA, R.S. Balanço hídrico climatológico e classificação climática para o município de Balsas-MA. Revista Scientia Agraria, v.18, n.1, p.83-89, 2017a.
PASSOS, M.L.V., RAPOSO, A.B., MENDES, T.J. Estimativa da distribuição da precipitação pluviométrica provável em diferentes níveis de probabilidade de ocorrência. Revista Brasileira de Agricultura Irrigada, v.11, n.1, p.1106-1115, 2017b.

PASSOS, M.L.V., ZAMBRZYCKI, G.C., PEREIRA, R.S. Balanço hídrico e classificação climática para uma determinada região de Chapadinha-MA. Revista Brasileira de Agricultura Irrigada, v.10, n.4, p.758766, 2016.

ROLIM, G.S., CAMARGO, M.B.P., LANIA, D.G., MORAES, J.F.L. Classificação climática de Köppen e de Thornthwaite e sua aplicabilidade na determinação de zonas agroclimáticas para o estado de São Paulo. Bragantia, Campinas, v.66, n.4, p.711-720, 2007.

SANTOS, G.O., HERNANDEZ, F.B.T., ROSSETTI, J.C. Balanço hídrico como ferramenta ao planejamento agropecuário para a região de Marinópolis, noroeste do estado de São Paulo. Revista Brasileira de Agricultura Irrigada, v.4, n.3, p.142-149, 2010.

SILVA, V.P.R., PEREIRA, E.R.R., AZEVEDO P.V., SOUSA, F.A.S., SOUSA, I.F. Análise da pluviometria e dias chuvosos na região Nordeste do Brasil. Revista Brasileira de Engenharia Agrícola e Ambiental, v.15, n.2, p.131-138, 2011.

SOUZA, A.P., MOTA, L.L., ZAMADEI, T., MARTIM, C.C., ALMEIDA, F.T., PAULINO, J. Classificação Climática e Balanço Hídrico Climatológico no Estado de Mato Grosso. Nativa, Sinop, v.1, n.1, p.34-43, 2013.

THORTHWAITE, C.W. An approach towards a rational classification of climate. Geographical Review, London, v.38, p.55-94, 1948.

THORTHWAITE, C.W., MATHER, J.R. The water balance. Publications in Climatology. New Jersey: Drexel Institute of Technology, 1955, 104p. 